\title{
Similar services, different perceptions: The gaps of satisfaction based on the level of recreation specialization
}

\author{
Sun-Hwan Hwang \\ University of Seoul, Department of Sport Science, Seoul, 130-743, Republic of Korea \\ Sangwoo In ${ }^{*}$ \\ Myongji University, College of Arts and Physical Education, Gyeonggi-do, 449-728, Republic of Korea
}

\begin{abstract}
The golf industry has become the center of attention for recreational activities in the participant sport market; however, there has been little effort made to understand golf consumer and their consumption behavior using the concept of 'recreational specialization' which segments the golfers based on level of specialization in golf. The purpose of this study was to explore the differences in the relationships among perceived service quality, price of playing golf, overall customer satisfaction with the course, and a player's intention to revisit the same golf course based on the magnitude of recreation specialization in golf. Four public and two private golf courses from the southeastern state of the United States were randomly chosen from a list in a golf magazine. The 365 surveys among 417 participants were ultimately analyzed. Multiple group analysis was conducted in order to investigate differences in relationships among service quality, price, customer satisfaction, and revisit intentions between groups based on the level of recreation specialization. The key findings were 1) for more specialized golfers, satisfaction with price did not affect overall customer satisfaction or revisit intention, however, service quality significantly influenced both overall customer satisfaction and revisit intention, 2) for less specialized golfers, satisfaction with price significantly influenced overall customer satisfaction but did not affect revisit intention. Knowledge about which the determinants of satisfaction are different between more and less specialized golfers could provide a better understanding of how different marketing strategies should be implemented for different specialized levels of golfers.
\end{abstract}

Keywords: Recreation Specialization, Consumer Behavior, Service Quality, Participant Sport Industry

\section{INTRODUCTION}

The golf industry is one of the major individual sport markets; it involves more than 105 million self-professed fans and 36 million people's participation in the United State [58] and, 4.4 million registered players in Europe [33]. According to the National Golf Foundation [46], [47], the total number of rounds played in the United States had steadily increased between 2003 and 2008. However, the number has been steadily decreasing since 2008. Furthermore, the total number of golfers and the number of rounds played by core golfers those who play golf more than eight times a year have decreased recently [47]. The European golf market faced a similar crisis in golf participation in the 2011 financial year, its first fall in participation in more than two decades [33]. The decrease of participants in the world of golfing has been linked with negative result in financial indices of golf clubs; for example, about $15 \%$ of private golf courses (approximately

* Corresponding author, Email : sangwoo.in@mju.ac.kr Manuscript received Dec. 04, 2012; revised Mar 04, 2013; accepted Mar 14, 2013
4,400 clubs) in the United States are facing financial deficits [61].

The market competition among golf courses has become more intense [65], fuel costs are increasing, and the global economy is sluggish. Thus, it has become more critical for golf course managers to understand what they should be doing to create a competitive advantage for themselves in the golf market. It would be particularly useful for golf course managers to understand what factors influence golfers to (re)visit their golf courses and how to retain current customers.

Despite the popularity of golf as a recreational sport and the importance of the golf industry as a key facilitator for participant sport, there has been little effort to understand golf consumers and their consumption behaviors by segmentation of golfers using the concept of 'recreation specialization' [52], [53], [65]. Recreation specialization is the concept used to explain the factors driving the diversity of participants within any given activity [10]. According to [10], there are distinct classes of participants (i.e., "a continuum of behavior from the general to the particular", p.175) who will accordingly exhibit distinct styles of involvement, such as skills, equipment and setting preferences, attachment to the activity, attitudes toward 
management practices and the social context.

Recreation specialization includes three dimensions, i.e., the behavioral, cognitive, and affective dimensions. Sports participants are considered more or less specialized according to the how high or low of a value they old in the composite number of these three dimensions. Different degrees of specialization among consumers may result in different perceptions toward similar kinds of services. Therefore, the concept of recreation specialization could have significant implications in explaining the diversity of golfers and their consuming behavior, as well as the diversity of perceptions regarding the quality of services of golf service providers.

However, in the context of golf, researches addressing customers' different level of recreational behavior based on their specialization have been remained marginal to the sport management discipline as a whole. Only a few studies have attempted to illustrate the connection between quality of service and the satisfaction of those who play golf more versus less seriously, using a concept similar to that of 'recreation specialization.' Several studies have shown that the overall level of satisfaction related to quality of service is related to price factors, i.e., green fees, and that the relationship between quality of service and price potentially has a significant impact on a player's intention to return to that particular location [28]. Given the importance of satisfaction for retaining consumers and the fact that consumers may have different perceptions of overall satisfaction with pricing, understanding the determinants and differences of satisfaction among both more and less specialized golfers would give useful insights to course managers who are interested in developing a strategic marketing plan, and/or for conducting a personalized marketing plan that considers the diversity in the recreational levels of the participants.

The purpose of the study was to explore the perceived differences in the relationships among quality of service, price, customer satisfaction and course revisit intention based on the magnitude of recreation specialization. For this study, [15]'s model of the relationships among perceived service quality, customer satisfaction, and repurchase intention was used as a fundamental framework. In addition, [50]'s components of service evaluation (i.e., SERVQUAL) was modified to measure the quality of service in a golf context. It noted that golfers often consider green fees as a determinant when selecting a golf course [28]. Based on these studies, price was added as a significant factor that could influence customer satisfaction.

Our expectation was that clarifying the effects of these determinants on both overall satisfaction and revisit intentions based on the level of recreation specialization would have a pivotal role in strategic marketing planning for attracting, serving and retaining customers.

\section{LITERATURE REVIEW}

Quality of service and the price have been referred to as determining factors influencing the choice of a service and the retention of existing customers [3], [11], [15], [19], [27], [31], [50]. These influencing factors have been widely used in service marketing studies, such as retail, (e.g., [41]) or tourism (e.g., [2]) to evaluate performance; and it have been said that the golf industry is a similar kind of service industry.

If we think more about the relationships and structures between service provider and consumer, however, golf involves a different type of service when compared to these other types of industry because that it always requires the participation of the consumer in creating the service. Therefore, level of consumer participation would be one of the determinants in total perceived satisfaction of the quality of service. At this point, it is necessary to address some questions; 1) Are there unique features in the relationships among the quality of service, satisfaction and revisit intention in a participation sport? 2) Does the price, as a reward from the service provided, have an influence on the satisfaction and revisit intention? 3) Does the participant's level of experience have an effect on the perception of satisfaction when comparing similar levels of service? If so, what are the key factors that make the perception different? The answer for these questions could be found by turning to the Expectation Confirmation Theory (ECT) [49], previous research (e.g., [5], [66]) on the Satisfaction with Price on Overall Satisfaction and Revisit Intention and the concept of Recreation Specialization [10].

\subsection{ECT and the Participation Sports Industry}

ECT posits that prior expectations interplay with perceived performance and lead to post-purchase satisfaction [49]. If the perceived performance of a product (a good or service) exceeds expectations, a consumer will be satisfied post-purchase, which will likely result in repurchase. ECT has been widely utilized in the consumer behavior literature, which investigates consumer satisfaction, post-purchase behavior (repurchase intentions) and service marketing in general [1], [16], [48], [49], [51], [64].

The construct of ECT consists of five main components: expectation, perceived performance, confirmation, satisfaction, and repurchase intention. Several studies have reported on the phases of ECT, from expectation through repurchase intention [1], [4], [48], [49]. According to the theory, consumers shape their initial expectations about specific products or services prior to purchase. Second, after accepting and using that product or service, they experience initial consumption. In turn, they form a perception about the performance. Third, they evaluate the perceived performance compared with their initial expectation, determining the extent to which their initial expectation is confirmed or disconfirmed. Fourth, they experience a level of satisfaction based on their (dis)confirmation level. Finally, satisfied consumers form a repurchase intention, whereas dissatisfied customers stop purchasing the product or using the service.

In the golf context, a golfer forms an initial expectation of the golf course's service quality prior to using the course. During the first golf experience at a course, the user forms a perception about the course's quality of service. At the same time, the golfer evaluates the perceived course performance vis-à-vis his or her original expectation of service quality and decides whether his or her expectation is confirmed. At this point, service quality is regarded as an important determinant of satisfaction within the golf experience. Next, the golfer assesses his or her satisfaction based on the initial expectation and perceived performance of the golf course. Finally, a 
satisfied golfer is more willing to revisit the same golf course, while a dis-satisfied golfer may quit using the golf course and potentially find alternatives.

According to ECT, a golfer who holds a lower expectation and/or who had a higher perceived performance is more likely to be more satisfied with his or her experience and, in turn, be a loyal customer of the golf course. Inversely, higher expectations and/or lower performance are more likely to cause disconfirmation, which negatively influences customer satisfaction and repurchase intention. With a golf experience, a golfer who has higher expectations and/or who perceived a lower performance is more inclined to be dissatisfied with his or her experience and may stop using the course and seek out more appropriate golf courses.

Many studies regarding repurchase intention as a final decision reflecting satisfaction have shown that there are strong relationships with other factors, including service quality, customer satisfaction, switching barriers, brand trust and commitment, and price (e.g., [26], [45], [66]). Of these factors, service quality, price and customer satisfaction are the most likely to be primary determinants of revisit intention for leisure facility customers [55], [63]. Numerous studies have reported a positive relationship between overall satisfaction and repurchase (revisit) intention [5], [24], [38]. However, satisfaction is a qualitatively different construct from repurchase intention because it can be evaluated using only cognitive and affective dimensions, whereas repurchase intention also has a behavioral component. In addition, satisfaction is a relatively subjective construct, combining the experience of a provided service and the actual performance of an individual in the participation sport, such as in golf. Therefore, it would be necessary to measure whether the positive relationships among service quality, overall satisfaction and revisit intention are applicable in the context of a participation sport. For this reason, the relationship between customer satisfaction and revisit intention was investigated in this study. These rationales lead to the following set of hypotheses:

H1: Service quality has a positive influence on overall satisfaction with a golf course.

$\mathrm{H} 2$ : Service quality has a positive influence on revisit intention with a golf course.

H3: Overall satisfaction has a positive influence on revisit intention to a golf course.

\subsection{Effects of Price Satisfaction on Overall Satisfaction and Revisit Intention}

According to the service quality literature, service quality, satisfaction and repurchase intention are the primary factors used in marketing studies for understanding consumer behavior [7], [14], [21]. In addition to these factors, price is a major element impacting consumer behavior [13]. Many researchers have shown that price is significantly related to consumer satisfaction and repurchase intention in a variety of contexts, such as travel [19], dining [20], internet shopping [12] and retail banking [40], [41]. However, just a limited number of studies (e.g., [19], [40]) have presented the relationship between quality of service and price satisfaction as primary factors in overall consumer satisfaction and repurchase intention. In general, the price of a product or service represents the value that a consumer actually places on the product or service. Therefore, an understanding of the relationship between the objective price and subjective satisfaction is critical for understanding behavior patterns of sport consumers. For this reason, the basic model should be demonstrated in the context of golf so as to explore the relationship among service quality, price and repurchase intention. These rationale leads to the following hypotheses:

H4: Satisfaction with price has a positive influence on overall satisfaction with a golf course.

H5: Satisfaction with price has a positive influence on revisit intention with a golf course.

\subsection{Recreation Specialization}

Once people participate in a particular recreational or leisure activity, their level of interest in and commitment to the activity may change over time according to a variety of factors, including their relationships with other participants, the acquisition of necessary or advanced skills and knowledge, family support, and physical condition. Some will remain committed to the activity, whereas others will become less committed and will eventually give up and find another activity.

The term recreation specialization was conceived as a way to describe this process that entails change over time [10], [34], [42]. [10] refers to specialization as "a continuum of behavior from the general to the particular, reflected by equipment and skills used in the sport and activity setting preferences" (p. 175). [57] defined it as "a process that entails a progression in how recreationists participate in and view the activity over time" (p. 357). Also, they argued their concept of recreation specialization based on the idea that participant involvement in a leisure activity that shifts over time as reflected by the focusing of behavior, the acquisition of skills and knowledge, and the tendency to become so committed to the activity that it becomes a central life interest.

Researchers in leisure and recreation studies have demonstrated that recreationists along the specialization continuum vary significantly in terms of environmental attitudes [17], place attachment [8], motivations [42], attitudes toward depreciative behaviors [35], resource conditions [59], setting preferences [56], perceptions about crowding [36], choice of destinations [44], use of information when planning trips [39], and other aspects of participation. The consumers in participation sports have different levels of specialization in each sport and may also have different perceptions on the quality of service, price and satisfaction, which affect their intentions to revisit a particular place based on their level of specialization. This research question leads to the following hypothesis:

H6: There are differences in the relationships among the quality of service, price, overall satisfaction and revisit intention with a golf course based on the level of golf specialization.

\subsection{Conceptual Model}

Based on the literature review, a conceptual model that represents the relationship among quality of service, price, overall satisfaction and revisit intention was proposed (Figure 
1). A positively perceived service quality has a positive relationship with consumer satisfaction (H1) and revisit intention (H2). In addition, a positive perception of price influences satisfaction (H4) and revisit intention (H5). A high perceived satisfaction can increase consumer intention to repurchase (H3). Finally, it was posited that level of specialization in golf would influence the relationships among SQ, price, overall satisfaction, and revisit intention with a golf course (H6).

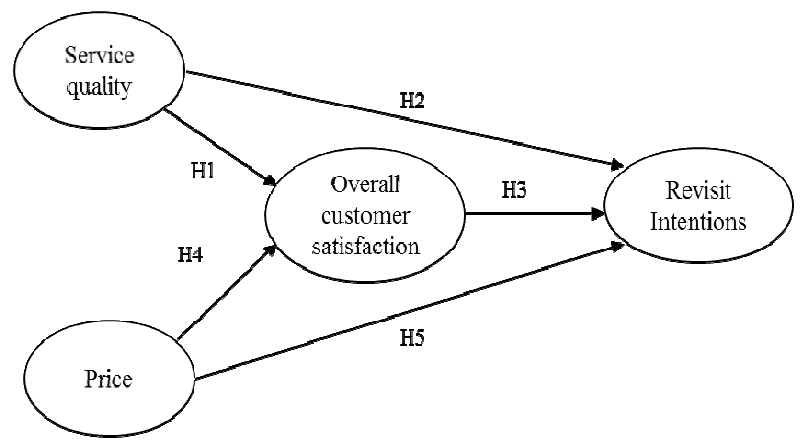

Fig. 1. Proposed model relationships among the latent variables

\section{METHOD}

\subsection{Participants}

Four public and two private golf courses in a southeastern state of the U.S. were randomly chosen from a list in a golf magazine, Golf Georgia. For avoiding any bias that might obtain from studying only a single and specific type of golf course, approximately 70 participants from each golf course were invited to complete the survey. The survey was distributed by researchers to golfers in the clubhouses and recess rooms after they finished their round and the golfers were asked to fill out an on-site self-administered questionnaire. Each survey was taken within 15 minutes. Respondents were 18 years old or older and unpaid volunteers, but researchers provided soft drinks.

A total of 417 golfers submitted surveys, of which 141 were collected at the private golf courses and 276 at the public golf courses. Of the 417 questionnaires collected, 52 were not included in the analyses because they had missed more than $50 \%$ on the recreation specialization scales. Thus, a total of 365 surveys were utilized in our analyses. The average age of the participants was 32.66 years $(\mathrm{SD}=11.85)$. Of the 365 participants, the majority were male (73.4\%) and Caucasian/White (51.2\%). The average annual household income was $\$ 74,790(\mathrm{SD}=43,878)$ with a median of $\$ 70,000$. In terms of expenditures, respondents spent $\$ 1,230$ annually on golf related items, including equipment and instruction. The average handicap score of respondents was $23(\mathrm{SD}=13.59)$.

\subsection{Instrumentation}

The instrument included scales to measure service quality, price, overall customer satisfaction, and revisit intentions. Additionally, the questionnaire included scales to determine recreation specialization in golf and demographic characteristics.

\section{Measuring Service Quality}

Service quality was measured with a modified version of the single item measurement model of service quality presented by [37]. Since they developed the service quality scale by considering the features of recreational sporting facility, it was decided that this model would be serve as a suitable starting point for the present study. For evaluating golf course service quality, it was necessary to modify their model and to include new concepts appropriate for the service quality construct. After generating an initial pool of items for service quality, these items were assessed by a panel of 21 experts composed of golf course managers and professional golfers. To obtain a panel of experts, the researchers contacted one golf course manager by phone and he was willing to introduce the researchers to 20 other experts. With the items modified by the panel, a pilot test was conducted with 151 golfers in two different golf courses (a private and a public golf course).

Based on the recommendations of a panel of experts and a pilot test, researchers finalized the measurement scales and 12 items for service quality were divided into three categories: program quality (three items), interpersonal quality (three items) and physical environment quality (six items). Some examples of these items are, "this club has a variety of classes/programs" (program quality); "the staff demonstrates willingness to help me" (interpersonal quality); and "this golf course has excellent ambience" (physical environment quality). All items were measured with a Likert-type scale (1 - strongly disagree to 5 - strongly agree). The modified 12-item Service Quality Scale had acceptable reliability with coefficient alphas of $0.65,0.83$ and 0.81 , respectively.

\section{Measuring Satisfaction with Price}

By analyzing the items related to the perception of price at the golf course, four items that accounted for all potential costs were selected and designed to measure the satisfaction with price: (1) I am satisfied with the green fees of the golf course; (2) I am satisfied with the cart fee of the golf course; (3) I am satisfied with the price of merchandise provided by the golf course; and (4) I am satisfied with the price of food provided by the concession at the golf course. The response options ranged from "strongly disagree" (1) to "strongly agree" (5). The 4-item price scale was reliable with a coefficient alpha of 0.77 .

\section{Measuring Overall Customer Satisfaction and Revisit} Intention

Previous studies have shown that multiple items are a better measure of overall satisfaction than a single item [18]. Since the experiences of services provided by a golf course could be categorized into experience in the fields and experience in the clubhouse, two items were adapted for this study to examine the overall satisfaction of golfers according to the recommendation of a panel of experts: (1) I am satisfied with the golf experience at this golf course; and (2) I am satisfied with this golf course. Response options ranged from strongly disagree (1) to strongly agree (5). The 2-item overall 
satisfaction with the golf course measure had an acceptable reliability with a coefficient alpha of 0.88 .

The revisit intention scale was modified from the model of [52] and the model of [60] since they all developed and empirically tested scales in the context of golf and service industry. Based on the review of a panel of experts, a total of three items for revisit intention were measured in this study: (1) If I were to choose a golf course to play golf, I would choose this golf course again; (2) I would consider choosing this golf course to play golf again; (3) For my next golf experience, I am willing to play golf at this golf course rather than at other golf courses. The 3 -item revisit intentions scale had an acceptable reliability with a coefficient alpha of 0.88 .

\section{Measuring Recreation Specialization}

Recreation specialization was measured with a modified version of [43]'s scale, which has been widely used in recreation studies. Adapting McFarlane's scale is highly acceptable since it encompassing all the dimensions of specialization (i.e., behavioral, cognitive and affective dimensions). Some examples of items are: "How long have you played golf?" (behavioral); "I think I have good golf skills" (cognitive); and "Golf is one of the most satisfying things I do" (affective). The alpha coefficient reliability values for recreation specialization were $0.65,0.85$ and 0.93 , respectively, for the behavioral, cognitive and affective dimensions.

\subsection{Procedure of Statistical Analyses}

Structural equation modeling (SEM) has a confirmatory factor analysis (measurement model) component and a path analysis (structural model) component [6]. The present study consisted of three primary steps: (1) testing the measurement model, (2) examining relationships among service quality, price, overall customer satisfaction and revisit intention (hypotheses 1 through 5) and (3) comparing these relationships between two groups (more and less specialized golfers) based on the level of recreation specialization in golf (hypothesis 6).

Measurement model testing was performed to determine if the chosen indicators were appropriate for the model. With the revised items based on a panel of experts and a pilot test, confirmatory factor analysis (CFA) using SPSS 15.0 and LISREL 8.51 tested the validity and reliability of the survey items to ensure that the scale items reflected their intended underlying constructs in the golf context. Second, for hypotheses 1 through 5, the structural model was tested using path analysis to investigate the relationships among the latent variables by identifying the direct and indirect effects [62].

Finally, to compare the relationships among the latent variables based on the levels of recreation specialization of the participants, the Multiple Group Analysis of SEM (MGASEM) was applied to test hypothesis 6 . Accordingly, the sample size was reduced to half or less, but the number of parameters per group was not reduced in the model testing. In this case, the power issue had potential to be a serious problem because many estimates must identify with a small sample [25]. Thus, the sample size needed to be enlarged or the number of parameters needed to be decreased to maintain eligible power. Using parceled data is useful to reduce the number of parameters when the sample size cannot be changed.
In the analysis, using the K-means cluster analysis, the entire sample was divided into two groups: more specialized and less specialized golfers. With these divided participants, the structural model was examined using SEM with LISREL 8.51. Then the structural models for all group were compared in order to investigate the differences in relationships among the latent variables.

According to [29], [30], the following three steps should be followed for group-based comparison. First, the path coefficients of each structural model in multiple groups should be examined. Second, the factor structure should be examined to identify whether the two models have the same pattern. Finally, the Chi-square $\left(\chi^{2}\right)$ result with the imposition of crossgroup equality constraint on each direct effect was compared with the Chi-square result with no constraint. A Chi-square result change $\left(\Delta \chi^{2}\right)$ greater than 3.84 between the two models indicated a statistically significant difference in the direct effects between the recreation specialization-based models. Therefore, the differences in the remaining direct effects between the two groups were investigated.

\section{RESULTS}

\subsection{Measurement Model}

In order to investigate the validity of the proposed model, a CFA was conducted. Overall, the measurement model test showed a good model fit, suggesting that the chosen indicators loaded on the construct in an appropriate manner. All three fit indices demonstrated a good model fit, $\chi^{2} / \mathrm{df}=2.28$, RMSEA $=$ 0.06 and CFI $=0.97$ [9], [22]. These goodness-of-fit statistics indicated that the proposed measurement model was valid (Table 1).

Table 1. Summary of the Measurement Model Fit Indices

\begin{tabular}{cccc}
\hline Model & RMSEA & CFI & $\chi^{2} / d f$ \\
\hline $\begin{array}{l}\text { Service } \\
\text { Quality }\end{array}$ & .059 & .97 & 2.28 \\
\hline
\end{tabular}

Note. RMSEA = Root mean square error of approximation; $\mathrm{CFI}=$ Comparative fit index; $\chi^{2} / d f=$ Normed chi-square.

\subsection{Structural Model}

Given the acceptable fit of the model, direct, indirect and total effects were investigated. All path coefficients are provided in Figure 2, and direct, indirect, and total effects for the final model of latent factors are presented in Table 2. 69\% of the variance in customer satisfaction was explained by the determinants of service quality and price, and $55 \%$ of the variance in revisit intentions was explained by the determinants of service quality, price and customer satisfaction.

As shown in Figure 2, perceived service quality had a statistically significant positive effect on overall customer satisfaction $(\mathrm{p}<0.05, \mathrm{z}=9.48)$. Satisfaction with price had a positive influence on overall customer satisfaction but was not statistically significant $(\mathrm{p}>0.05, \mathrm{z}=1.94)$. Perceived service quality had a statistically significant positive effect on revisit 
intentions $(\mathrm{p}<0.05, \mathrm{z}=3.82)$. Satisfaction with price had a positive effect on revisit intentions but it was not statistically significant $(\mathrm{p}>0.05, \mathrm{z}=0.83)$. Finally, overall customer satisfaction had a statistically significant positive influence on revisit intentions $(\mathrm{p}<0.05, \mathrm{z}=3.42)$. This model had an acceptable fit of the data $\left(\chi^{2} / \mathrm{df}=2.77\right.$, RMSEA $=0.07, \mathrm{CFI}=$ $0.91)$.

Table 2. Standardized Direct, Indirect, and Total Effects for the Model

\begin{tabular}{ccccc}
\hline Outcome & Determinant & Direct & Indirect & Total \\
\hline OCS & SQ & $.79^{* *}$ & -- & $.79^{* *}$ \\
OCS & PR & .09 & -- & .09 \\
RI & SQ & $.40^{* *}$ & $.28^{* *}$ & $.68^{* *}$ \\
RI & PR & .04 & .03 & .08 \\
RI & OCS & $.36^{* *}$ & -- & $.36^{* *}$ \\
\hline
\end{tabular}

Note. $\mathrm{SQ}=$ Service quality; $\mathrm{PR}=$ Price $;$ OCS $=$ Overall customer satisfaction; RI $=$ Revisit intentions. ${ }^{* *} p<0.01$

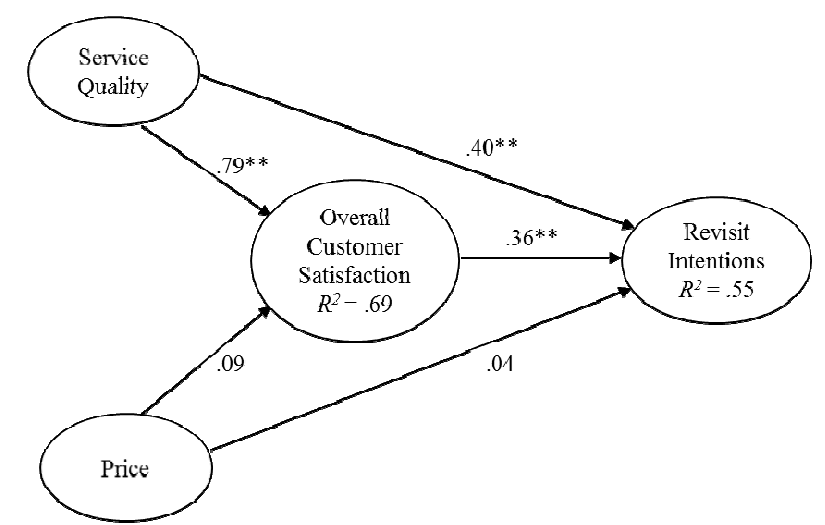

Fig. 2. Structural model testing relationship among service quality, price, overall customer satisfaction, and revisit intentions $(N=365)$. ${ }^{* *} p<.01$.

\subsection{Multiple Group Analysis}

Multiple group analysis was conducted in order to investigate differences in relationships among service quality, price, customer satisfaction, and revisit intentions between groups based on the level of recreation specialization. First, all participants were divided into two groups of more specialized and less specialized golfers by a K-means cluster analysis using three indices, including affective, cognitive and behavioral dimensions (Table 3). The first group consisted of less specialized golfers $(n=184)$, while the rest of the respondents were classified as more specialized golfers $(n=181)$. Table 2 lists the mean scores and standard deviations (SDs) of recreation specialization items for the two groups.

Table 3. Cluster Analysis for Recreation Specialization

\begin{tabular}{ccc}
\hline \multirow{2}{*}{ Dimension } & \multicolumn{2}{c}{ Mean $(S D)$} \\
\cline { 2 - 3 } & $\begin{array}{c}\text { Less Specialized } \\
\text { Golfers }(n=184)\end{array}$ & $\begin{array}{c}\text { More Specialized } \\
\text { Golfers }(n=181)\end{array}$ \\
\hline Affective & $2.55(0.49)$ & $3.80(0.48)$ \\
Cognitive & $2.13(0.65)$ & $3.64(0.76)$ \\
Behavioral & $4.52(4.48)$ & $13.75(10.05)$ \\
\hline
\end{tabular}

Second, the path coefficients of each structural model for the multiple groups were examined with correlations and SDs for both groups (Table 4 and Figure 3). For more specialized golfers, satisfaction with price did not affect overall customer satisfaction or revisit intention. However, service quality significantly influenced both overall customer satisfaction and revisit intention. Also, overall customer satisfaction significantly affected revisit intention. For less specialized golfers, satisfaction with price significantly influenced overall customer satisfaction but did not affect revisit intention.

Table 4. Correlations and Standard Deviations for Analysis of a Path Model

\begin{tabular}{|c|c|c|c|c|c|c|}
\hline \multirow[b]{2}{*}{ Variable } & & \multirow[b]{2}{*}{1} & \multirow[b]{2}{*}{2} & \multirow[b]{2}{*}{3} & \multicolumn{2}{|c|}{ More Specialized } \\
\hline & & & & & 4 & $S D$ \\
\hline 1. SQ & & -- & $.46^{* *}$ & $.70^{* *}$ & $.64^{* *}$ & 5.86 \\
\hline 2. PR & & $.19^{*}$ & -- & $.28^{* *}$ & $.31^{* *}$ & 3.22 \\
\hline 3. OCS & & $.65^{* *}$ & $.35^{* *}$ & -- & $.62^{* *}$ & 1.56 \\
\hline 4. RI & & $.55^{* *}$ & $.23^{* *}$ & $.58^{* *}$ & -- & 2.33 \\
\hline $\begin{array}{l}\text { Less } \\
\text { Specialized }\end{array}$ & $S D$ & 6.14 & 3.17 & 1.65 & 2.44 & \\
\hline
\end{tabular}

Note 1. More specialized group (upper diagonal) and less specialized (lower diagonal)

Note 2. $\mathrm{SQ}=$ Service quality; $\mathrm{PR}=$ Price OCS $=$ Overall customer satisfaction; RI = Revisit intentions. $n 1=181$ More Specialized golfers; $n 2=184$ Less Specialized golfers.

Note 3 . * $p<0.05, * * p<0.01$

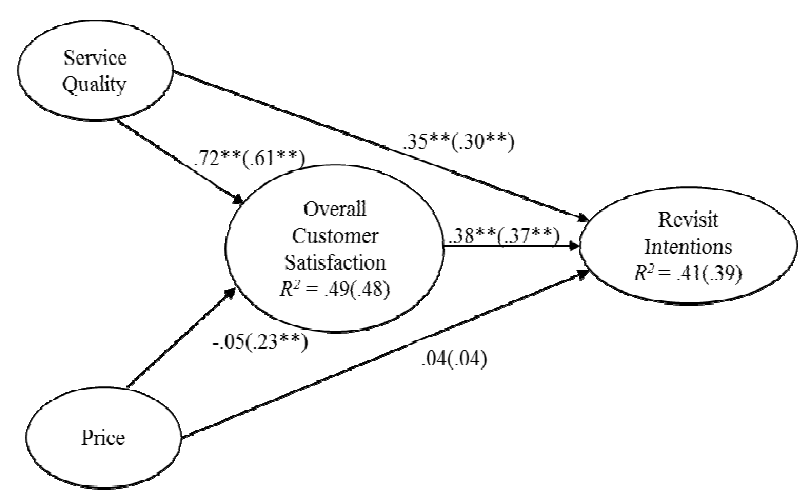

Fig. 3. Results of structural equation model for two groups testing relationships among latent variables.

Note. The parameter estimates in this figure are unstandardized values The values outside the parenthesis are for more specialized golfers and the values in the parentheses are for less specialized golfers. ${ }^{* *} \mathrm{p}<.01$.

Third, the factor structure was examined in order to identify whether the two models had the same pattern. If the two models had the same factor structure pattern, all five of the model's direct effects with the imposition of cross-group equality constraints were tested. Also, the goodness-of-fit indices were attained for the invariant path coefficient. The model fit indices, including $\chi^{2} / \mathrm{df}=2.75$, RMSEA $=0.09$, CFI $=$ 0.98 , NFI $=0.97$ and NNFI $=0.96$, supported the acceptability of this model. Finally, the Chi-square with imposition of crossgroup equality constraint on each direct effect was compared with the Chi-square with no constraint (Table 5). According to [30], a value of Chi-square change $\left(\Delta \chi^{2}\right)$ greater than 3.84 means that the difference between two groups is acceptable (p 
$<0.05)$. One of these indices, $\chi^{2}(1)=11.191$ for the path from price to overall customer satisfaction, was statistically significant $(\mathrm{p}<0.05)$. However, the other indices were not statistically significant. Therefore, the only significant difference between the two groups was in the relationship between price and overall customer satisfaction.

Table 5. Results of Multiple Group Analysis Comparisons of Two Groups on Parameter Estimates

\begin{tabular}{|c|c|c|c|c|}
\hline \multirow[b]{2}{*}{ Direct Effects } & \multirow[b]{2}{*}{$\chi^{2}$} & \multirow[b]{2}{*}{$\chi^{2}$ change } & \multicolumn{2}{|c|}{$\begin{array}{c}\text { Path Coefficients of } \\
\text { Separate Sample Analysis }\end{array}$} \\
\hline & & & $\begin{array}{c}\text { More } \\
\text { Specialized } \\
\text { Golfers }\end{array}$ & $\begin{array}{c}\text { Less } \\
\text { Specialized } \\
\text { Golfers }\end{array}$ \\
\hline $\mathrm{SQ} \rightarrow \mathrm{OCS}$ & 13.727 & .036 & $.72 * *$ & $.61^{* *}$ \\
\hline $\mathrm{PR} \rightarrow \mathrm{OCS}$ & 2.572 & $11.191^{* *}$ & -.05 & $.23^{* *}$ \\
\hline $\mathrm{SQ} \rightarrow \mathrm{RI}$ & 13.156 & .607 & $.35 * *$ & $.30^{* *}$ \\
\hline $\mathrm{PR} \rightarrow \mathrm{RI}$ & 13.721 & .042 & .04 & .04 \\
\hline $\mathrm{OCS} \rightarrow \mathrm{RI}$ & 13.364 & .399 & $.38^{* *}$ & $.37 * *$ \\
\hline
\end{tabular}

\section{DISCUSSION}

\section{Leveraging Service Quality}

There were positive relationships between service quality, overall satisfaction and revisit intentions, and we also found that service quality is one of the critical determinants for overall satisfaction and revisit intention. These findings support previous studies on the relationship between satisfaction and revisit intention (e.g., [5], [24], [45]) and on the role of service quality in customer retention (e.g., [7], [15], [19], [31]).

Service quality, in this study, noted a combination of physical environment, interpersonal and program qualities. Even though the management of service quality could have a critical role in retaining customers, it is not easy to manage service quality in practice. Managing a facility or environment in a certain way might be positively affects customer satisfaction with the quality. However managing physical environment is often associated with a large financial investment or, more likely, is difficult to change in short terms. In addition, individual satisfaction level with service may vary because it is influenced by subjective and relative processes achieved by comparing and evaluating with other similar services. These facts indicate that the degree of satisfaction with service quality will be changed at any time, and the service provider should try to assure a similar level of services to the customers continuously, depending on their needs.

Because the perceptions of service quality and overall satisfaction could be formed based on the degree of difference between the expected service quality and the actual service quality [4], [49], it is more important for a service manager to maintain a consistent service level rather than temporarily providing high quality services. Furthermore, it is important to set the minimum level of service quality that will be provided by the facility and manage it in such a way that will lead to repeat visits.

\section{Satisfaction with Price and Recreational Specialization}

The results of this study shows that the price is not always a critical factor in overall customer satisfaction or revisit intention. These findings are interesting because they are in opposition to previous research claims stating that price is the critical determinant in satisfaction and revisit intentions (e.g., [19], [20], [40], [41]. In addition, our results also indicate that there are differences between the less specialized golfer and the more specialized golfer in terms of the relationship between satisfaction with price and overall satisfaction. For the less specialized golfers, satisfaction with price significantly influenced overall customer satisfaction but did not affect revisit intention.

From the results of this study, it is reasonable to assume the following. First, more specialized golf consumers typically regard the prices of golf courses as reasonable and do not focus on the costs associated with the courses. This explanation is supported by [28] and [54], who concluded that golfers who have loyalty to the local golf course are likely to agree with the price and are mostly satisfied with the current price of the golf course. This assumption implies that the course manager should make an effort to ensure stable service fees (e.g., green fees, cart fee, merchandise fee, food, etc.). As the dynamics of market competition and social/economic issues may lead to an unexpected rise in costs in the golf industry, managers also need to develop various low price packaging services and reduce unnecessary service costs.

Second, it could be assumed that golfers already consider prices when they evaluate service quality. At the same time the golfers may perceive the overall satisfaction and revisit intentions from the service quality in which included the total experiences of service than from single and particular service items such as price. Overall satisfaction is the result of a feeling which could be measured by comparing perceived and expected performances [32]. Thus, there is some reason to believe that for enhancing overall satisfaction, the course manager should have strategies to develop detailed levels of pricing options by showing reference prices with each service and product to lead customers feel that each service is reasonably priced. Thirdly, golfers have different ways to measure overall satisfaction based on their individual specialization level. Our results demonstrate that only less specialized golfers relate satisfaction with price as a determinant of overall customer satisfaction. In other words, more specialized golfers tend to base satisfaction on the overall experience rather than price. This supports previous research from the tourism industry that state that higher specialized individuals were more interested in the total experience [23]. The fact that more specialized golfers are less sensitive to price than the less specialized golfer could be because more specialized golfers have a longer history of participation than less specialized golfers or because more specialized golfers are interested in the experience and do not consider cost factors. Managers should understand the different perceptions in regard to price and satisfaction by the level of specialization in golf. For the less specialized golfers, the manager needs to offer a variety of promotional programs related to price to encourage future visits. However, for the more specialized golfer, it is important to focus more on the environment of play so that 
these kinds of golfers are likely to have more authentic experiences. For example, the periodic hosting of well-known golf events or giving players a chance to experience the courses used by famous players would help to enhance the level of overall satisfaction.

\section{Future Studies}

There are some limitations in this research. First, the golf courses selected in this study are not representative of all golf courses throughout the world. Other countries might have relatively high pricing policies if they have limited service facilities compared to the demand of playing golf within that country. In these situations, the findings of similar research would likely be different since there is high probability that the role of price may be a more critical constraint to participation in golf within those countries. Second, there may be other factors that influence customer revisit intention apart from factors suggested in this study, such as demographic characteristics or distance to the golf course. Third, this study did not consider the potential effect of loyalty to a golf facility that may influence on revisit intension. Even though we tried to remove biases of membership effect by asking participants about intentions in the future revisit, the registered golfers' membership and their loyalty lead to different results in terms of their revisit intentions and/or satisfaction with price.

Future research should investigate the cultural and social factors of sport participants, ideally while accounting for the limitations mentioned above. Models to test other demographical segment and other types of participation sports such as bowling, tennis, baseball, and others, are also needed. Furthermore, the study of personalizing marketing strategies according to the level of specialization in a certain sport would be helpful for managers of participant sport, along with developing appropriate research models to confirm the findings of this study.

\section{REFERENCES}

[1] Anderson, E. W., \& Sullivan, M. W., "The antecedents and consequences of customer satisfaction for firms. Marketing Science," vol. 12, no 2, 1993, pp. 125-143.

[2] Barsky, J. D, "Customer satisfaction in the hotel industry: Meaning and measurement," Hospitality Research Journal, vol. 16, no 1, 1992, pp. 51-73.

[3] Berry, L. L., Zeithaml, V. A., \& Parasuraman, A., "Five imperatives for improving service quality," Sloan Management Review, vol. 31, 1990, pp. 29-38.

[4] Bhattacherjee, A., "Understanding information systems continuance: An expectation-confirmation model," MIS Quarterly, vol. 25, 2001, pp. 351-370.

[5] Bloemer, J., \& De Ruyter, K., "On the relationship between store image, store satisfaction and store loyalty," European Journal of Marketing, vol. 32, 1998, pp. 499513.

[6] Bollen, K. A., Structural equation with latent variables. New York: John Wiley \& Sons, 1989.

[7] Brady, M. K., \& Cronin, J. J., "Some new thoughts on conceptualizing perceived service quality: A hierarchical approach," Journal of Marketing, vol. 65, no. 3, 2001, pp. 34-49.

[8] Bricker, K., \& Kerstetter, D. L., "Level of specialization and place attachment: An exploratory study of whitewater recreationists," Leisure Sciences, vol. 22, 2000, pp. 233-257.

[9] Browne, M. W., \& Cudeck, R., Alternative ways of assessing model fit. In K. A. Bollen \& J. S. Long (Eds.), Testing structural equation models. Newbury Park, CA: Sage, 1993.

[10] Bryan, H., "Leisure value systems and recreational specialization: The case of trout fisherman," Journal of Leisure Research, vol. 9, 1977, pp. 174-187.

[11] Brady, M., \& Cronin, J., "Some new thoughts on conceptualizing perceived service quality: a hierarchical approach," Journal of Marketing, vol. 65, 2001, pp. 3449.

[12] Cao, Y., Gruca, T. S., \& Klemz, B. R., "Internet pricing, price satisfaction, and customer satisfaction," International Journal of Electronic Commerce, vol. 8, no. 2, 2004, pp. 31-50.

[13] Carlson, J. P., \& Weathers, D., "Examining differences in consumer reactions to partitioned prices with a variable number of price components," Journal of Business Research, vol. 61, no. 7, 2008, pp. 724-731.

[14] Chang, K., \& Lee, C., "Relationship among service quality, customer satisfaction, and renewal intentions in Health/Fitness clubs." International Journal of Sport Management, vol. 5, 2004, pp. 306-315.

[15] Cronin, J. J., Jr., \& Taylor, S. A., "Measuring service quality: A reexamination and extension," Journal of Marketing, vol. 56, no. 3, 1992, pp. 55-68.

[16] Dabholkar, P., Shepherd, C. D., \& Thorpe, D. I., "A comprehensive framework for service quality: An investigation of critical conceptual and measurement issues through a longitudinal study." Journal of Retailing, vol. 76, 2000, pp. 139-173.

[17] Dyck, C., Schneider, I., Thompson, M., \& Virden, T., "Specialization among mountaineers and its relationship to environmental attitudes," Journal of Park and Recreation Administration, vol. 21, no. 2, 2003, pp. 4462.

[18] Graefe, A. R., \& Fedler, A. J., "Situational and subjective determinants of satisfaction in marine recreational fishing," Leisure Sciences, vol. 8, 1986, pp. 275-295.

[19] Grewal, D., Hardesty, D. M., \& Iyer, G. R., "The effects of buyer identification and purchase timing on consumers' perceptions of trust, price fairness, and repurchase intentions," Journal of Interactive Marketing, vol. 18 , no. 4, 2004, pp. 87-101.

[20] Homburg, C., Hoyer, W. D., \& Koschate, N., "Customers' reactions to price increases: Do customer satisfaction and perceived motive fairness matter?," Journal of the Academy of Marketing Science, vol. 33, no. 1, 2005, pp. 36-49.

[21] Howat, G., Murray, D., \& Crilley, G., "The relationships between service problems perceptions of service quality, satisfaction, and behavioral intentions. Service Quality, vol. 5, no. 2, 1999, pp. 76-90. 
[22] Hu, L., \& Bentler, P. M., "Cutoff criteria for fit indexes in covariance structure analysis: Conventional criteria versus alternatives," Structural Equation Modeling, vol. 6, 1999, pp. 1-55.

[23] Jackson, R., \& Norton, R. C., "Phases: The personal evolution of the Sport hunter," Wisconsin Sportsman, vol. 9, no. 6, 1980, pp. 17-20.

[24] Jones, M. A., Mothersbaugh, D. L., \& Beatty, S.E., "Switching barriers and repurchase intentions in services," Journal of Retailing, vol. 76, no. 2, 2000, pp. 259-274.

[25] Jorëskëg, K. G., \& Sörbom, D. (1996). LISREL8: User's reference guide. Chicago: Scientific Software.

[26] Julander, C., \& Soderlung, R., "Effects of switching barriers on satisfaction, repurchase intentions and attitudinal loyalty," SSE/EFI Working Paper Series in Business Administration, vol. 1. 2003, pp. 1-22.

[27] Kelly, S. W, \& Turley, L. W., "Consumer perceptions of service quality attributes at sporting events," Journal of Business Research, vol. 54, 2001, pp. 161-166.

[28] Kim, Y., Young, A. M., Shin, H. K., \& Kim, C., "Price perceptions in the selection of golf course: a case study of municipal golf courses in the city of Albuquerque," Journal of Tourism Insights, vol. 1, no 1, 2010, pp. 65-72.

[29] Kline, R. B., Principle and practice of structural equation modeling, New York: The Guilford Press, 1998.

[30] Kline, R. B., Principles and practice of structural equation modeling (2nd ed.), New York: Guilford Press, 2005.

[31] Ko, Y. J., \& Pastore, D. L., "A hierarchical model of service quality for the recreational sport industry," Sport Marketing Quarterly, vol. 14, no. 2, 2005, pp. 84-97.

[32] Kotler, P., Marketing Management: 10th ed., New Jersey, Prentice-Hall, 2000.

[33] KPMG (2011). Golf participation in Europe. Retrieved Mar. 18, 2008, from http://static.golfbusiness community.com/media/1/ 8/4/1/1841.pdf.

[34] Kuentzel, W. F., "How Specialized is Specialization Research?," Journal of Leisure Research, vol. 33, no. 3, 2001, pp. 351-356.

[35] Kuentzel, W. F., \& Heberlein, T., "Does specialization affect behavioral choices and quality judgments among hunters?," Leisure Sciences, vol. 14, 1992, pp. 211-226.

[36] Kuentzel, W. F., \& McDonald, G., "Differential effects of past experience, commitment, and lifestyle dimensions on river use specialization," Journal of Leisure Research, vol. 24, 1992, pp. 269-287.

[37] Kwon, H., \& Ko, Y. J., "Validation of single item measurement of scale of service quality for recreational sport (SSQRS)," International Journal of Sport Management, vol. 7, 2006, pp. 112-122.

[38] Loveman, G. W., "Employee satisfaction, customer loyalty, and financial performance: An empirical examination of the service profit chain in retail banking," Journal of Service Research, vol. 1, 1998, pp. 18-31.

[39] Martin, S. R., "Specialization and differences in setting preferences among wildlife viewers," Human Dimensions of Wildlife, vol. 2, no 1, 1997, pp. 1-18.
[40] Matzler, K., Würtele, A., \& Renzl, B., "Dimensions of price satisfaction: a study in the retail banking industry," International Journal of Bank Marketing, vol. 24, no 4, 2006, pp. 216-231.

[41] McCabe, D., Rosenbaum, M. S.,\& Yurchisin, J., "Perceived service quality and Shopping motivations: A dynamic relationship," Services Marketing Quarterly, vol. 29 , no. 1, 2007, pp. 1-21.

[42] McFarlane, B. L., "Specialization and motivations of birdwatchers," Wildlife Society Bulletin, 22, 1994, pp. 361-370.

[43] McFarlane, B. L., "Recreation specialization and site choice among vehicle-based campers." Leisure Sciences, vol. 26. No. 3, 2004, pp. 309-322.

[44] McFarlane, B. L., Boxall, P. G., \& Watson, D., "Past experience and behavioral choice among wilderness users," Journal of Leisure Research, vol. 30, 1998. pp. 195-213.

[45] Mittal, V., \& Kamakura, W., "Satisfaction, repurchase intent, and repurchase behavior: Investigating the moderating effect of customer characteristics," Journal of Marketing Research, vol. 38, 2001, pp. 131-142.

[46] NGF, Golf facilities in the U.S. Retrieved November 18, 2006, from http://www.ngf.org.

[47] NGF, National rounds report 2009, National Golf Foundation, National Golf Foundation, 2010.

[48] Oliver, R. L., "A cognitive model of the antecedents and consequences of satisfaction decisions," Journal of Marketing Research, vol. 42, 1980, pp. 460-469.

[49] Oliver, R. L., "Cognitive, affective and attribute bases of the satisfaction response," Journal of Consumer Research, vol. 20, 1993, pp. 418-430.

[50] Parasuraman, A., Zeithaml, V. A., \& Berry, L. L., "Alternative scales for measuring service quality: A comparative assessment based on psychometric and diagnostic criteria," Journal of Marketing, vol. 70, no. 3, 1994, pp. 201-230.

[51] Patterson, P. G., Johnson, L. W., \& Spreng, R. A., "Modeling the determinants of customer satisfaction for business-to-business professional services," Journal of the Academy of Marketing Science, vol. 25, 1997, pp. 417.

[52] Petrick, J. F., \& Backman, S. J., "An examination of the construct of perceived value for the prediction of golf travelers' intentions to revisit," Journal of Travel Research, vol. 41, 2002a, pp. 38-45.

[53] Petrick, J. F., \& Backman, S. J., "An examination of the determinants of golf travelers' satisfaction," Journal of Travel Research, vol. 40, 2002b, pp. 252-258.

[54] Petrick, J.F., Backman, S.J., Bixler, R., \& Norman, W.C. , "Analysis of golfer motivations and constraints by experience use history," Journal of Leisure Research, vol. 33, 2001, pp. 56-70.

[55] Roh, D. Y., "Relationship among Service Quality, Service Value, Customer Satisfaction and Repurchase of Sport Center Consumer," Korean Journal of Sport Management, vol. 9. No. 4, 2004, pp. 71-88

[56] Scott, D., \& Thigpen, J., "Understanding the birder as tourist: Segmenting visitors to the Texas Hummer/Bird 
Celebration," Human Dimensions of Wildlife, vol. 8, 2003, pp. 199-218.

[57] Scott, D., \& Shafer, C. S., "A rejoinder to reviewers' comments," Journal of Leisure Research, vol. 33, no. 3, 2001, pp. 357-361.

[58] SGMA, 2010 sports and Fitness Participation Report, Sporting Goods Manufacturer Association. Retrieved March 19, 2012, from http://www.sgma.com/reports/ 266_2010-Sports-and-Fitness-Participation-Report--The-Complete-Version.

[59] Shafer, S. C., \& Hammitt, W. E., "Purism revisited: Specifying recreational conditions of concern according to resource intent," Leisure Sciences, vol. 17, 1995, pp. 15-30.

[60] Sierra, J. J., \& McQuitty, S., "Service providers and customers: social exchange theory and service loyalty," Journal of Services Marketing, vol. 19, 2005, pp. 392-400.

[61] Swartz. J., "Golf clubs suffer in recession as membership dwindles," USA today 08-03-2010, Retrieved from http://www.usatoday.com/money/economy/2010-08-03golf03_CV_N.htm

[62] Tate, $\overline{\mathrm{R}}$., An introduction to modeling outcomes in the behavioral and social sciences, Boston: Pearson Custom Publishing, 1998.

[63] Tsitskari, E., Tsiotras, D., \&Tsiotras, G., "Measuring service quality in sport services," Total Quality Management, vol. 17, no. 5, 2006, pp. 623-631.

[64] Tse, D. K., \& Wilton, P. C., "Models of consumer satisfaction formation: An extension," Journal of Marketing Research, vol. 25, 1988, pp. 204-212.

[65] Won, D., Hwang, S., \& Kleiber, D. "How do golfers choose a course? A conjoint analysis of influencing factors," Journal of Park and Recreation Administration, vol. 27, no. 2, 2009, pp. 1-16.

[66] Zboja, J.J., \& Voorhees, C.M. "The impact of brand trust and satisfaction on retailer repurchase intentions," Journal of Services Marketing, vol. 20, no, 5, 2006, pp. 381-390.

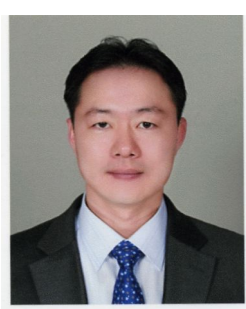

\section{Sun-Hwan Hwang}

He received the B.S., M.S in physical education from Seoul National University, Korea in 1996, 2001 respectively and also received Ph.D. in Recreation \& Leisure Studies from the University of Georgia, USA in 2008. Since then, he has been teaching at the University of Seoul, Korea as an assistant professor. His main research interests include serious leisure, recreation specialization, and camp.

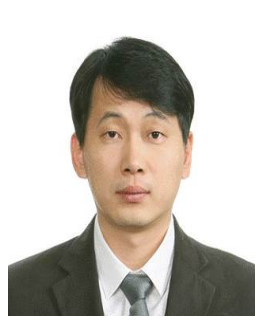

\section{Sangwoo In}

He received the B.S., M.S., and Ph.D degrees in Physical Education and Sport Management from Seoul National University in 1996, 2006, 2010, respectively. He worked as an IT consultant in the mega sport event such as FIFAWorldcup, Universiad and Asian Games for several years and is now an assistant professor in College of Arts and Physical Education, Myongji University. His main research interests are Sport and IT convergence, Sport Event Management, HCI in Sport, and Strategic Sport Management. 